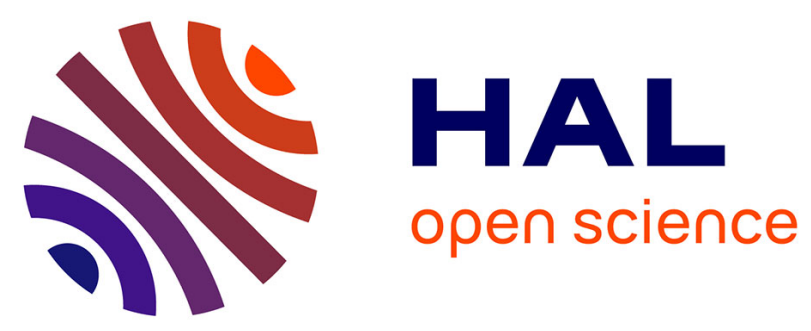

\title{
Experimental investigation of the air side fouling of finned tube heat exchangers
}

Denis Edelin, Nicolas Bariteau, Yoann Etourneau, Luc Traonvouez, Jérôme Soto

\section{- To cite this version:}

Denis Edelin, Nicolas Bariteau, Yoann Etourneau, Luc Traonvouez, Jérôme Soto. Experimental investigation of the air side fouling of finned tube heat exchangers. Heat and Mass Transfer, 2019, 55 (10), pp.2713-2722. 10.1007/s00231-019-02612-2 . hal-02372717

\section{HAL Id: hal-02372717 \\ https://hal.science/hal-02372717}

Submitted on 9 Jun 2021

HAL is a multi-disciplinary open access archive for the deposit and dissemination of scientific research documents, whether they are published or not. The documents may come from teaching and research institutions in France or abroad, or from public or private research centers.
L'archive ouverte pluridisciplinaire HAL, est destinée au dépôt et à la diffusion de documents scientifiques de niveau recherche, publiés ou non, émanant des établissements d'enseignement et de recherche français ou étrangers, des laboratoires publics ou privés. 


\title{
Experimental investigation of the air side fouling of finned tube heat exchangers
}

\author{
Denis Edelin ${ }^{1,2}$ (D) Nicolas Bariteau $^{3} \cdot$ Yoann Etourneau $^{2} \cdot$ Luc Traonvouez $^{4} \cdot$ Jérôme Soto $^{1,2}$
}

\begin{abstract}
Heat exchanger fouling is a major issue for heat transfer efficiency durability. In this study, we want to identify the evolution under fouling conditions of the performance of several geometries of finned tubes exchanger. We are particularly interested in whether it is preferable to choose an inefficient but easily cleanable heat exchanger over a more complex geometries that do not require cleaning. The article focusses on finned tubes heat exchangers that are dedicated to flue gas heat recovery from a chimney. In order to study several different configurations in controlled conditions, a test bench has been designed and manufactured. Heat transfer coefficients and the pressure drop of the different exchangers are calculated for an air flow of $190{ }^{\circ} \mathrm{C}$ and $6 \mathrm{~m} \cdot \mathrm{s}^{-1}$ with controlled dust injection. No pressure drop changes were observed during fouling tests for any of the heat exchanger configurations. This is probably due to the small thickness of the fouling layer and the modification of the external shape of the tubes by dust deposition that affects favorably the aerodynamic profile of the tubes. As expected, there is a typical exponential decrease in the heat transfer coefficients versus fouling time. When comparing the relative heat transfer decays during the fouling experiments for different heat exchanger configurations, it has be found that increasing the fins surface always improves the performance of the heat exchanger even when it is fouled.
\end{abstract}

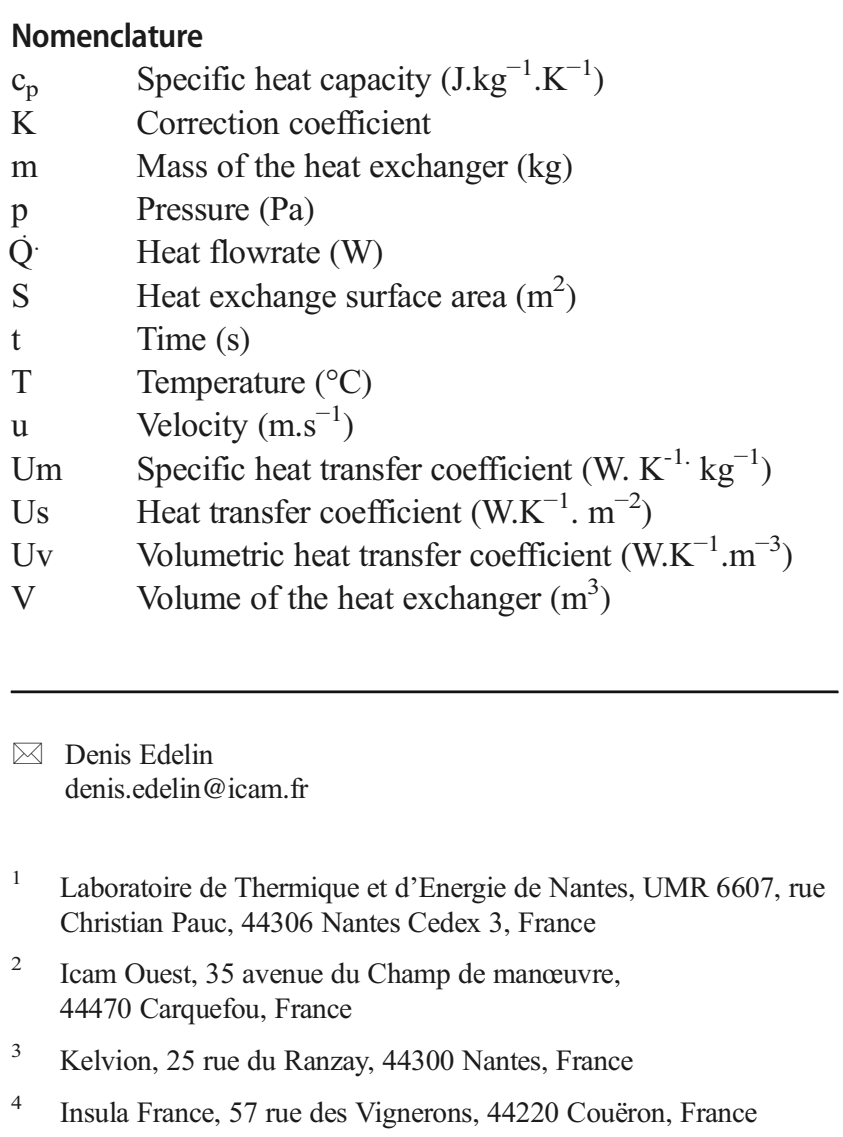

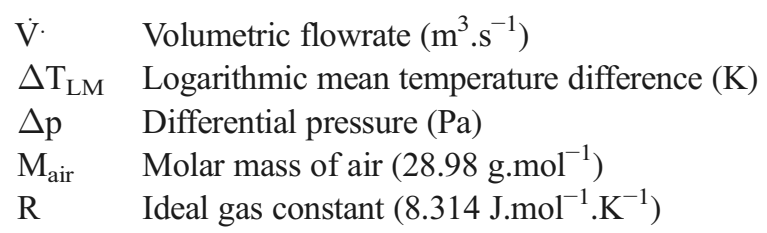

\section{Introduction}

Waste heat recovery plays an important role in the industry in order to reduce energy loss.

To meet the objectives of improving the energy efficiency of industries, waste heat recovery will have to play an even more important role in the future.

Heat exchangers are at the heart of facilities that recover heat from waste fluid for other uses. Therefore, the proper functioning of this equipment is crucial. 
However, these systems must often operate in harsh environments, where the fluid is loaded with contaminants causing the fouling of the exchanger.

Today a lot of studies have been done to improve the performance of heat exchangers in clean environments [1-3] and this mainly because it is difficult and complicated to study the impact of fouling.

Fouling is the main source of problems that can lead to a significant drop in the efficiency of the heat exchanger, or even to its dysfunction, resulting in serious economic consequences. That is why some people approach the problem through a risk analysis [4].

Therefore, it appears necessary to investigate the behaviour of fouling on the performance of heat exchangers.

The fouling of heat exchangers is a very broad topic because it results of the formation of a deposition layer whose composition (bio-film, organic matter, oxidation, dust deposit, limestone deposit, etc.), just like its consequences (lower heat transfer, higher pressure drop), vary enormously from one application to another.

Among the applications in development that require the study of fouling we can mention the heat pump system used for HVAC [5, 6], heat exchangers for recovering wastewater heat energy [7] or the recovery of heat energy from combustion exhaust gases [8]. Our study focuses on heat recovery applications from metallurgical smokes, which correspond to very hot gases $\left(>500^{\circ} \mathrm{C}\right)$ loaded with dust from the reduction of ore.

In this application framework, the fouling mechanism is mainly due to a suspension of particles. It is generally accepted that flue-ash particles are transported and then deposited on the exchanger by transport mechanisms such as turbulent diffusion, inertial impact, thermophoresis and condensation [9-11].

Today huge progress has been made on the modelling of fouling in this framework of applications. The work done by researchers from Xi' an Jiaotong University is very promising [12-17]. They have given clues on how to design heat exchangers that would be less subject to fouling.

Although numerical simulation is making progress, since the fouling is specific to each application and depends on the properties of the dust, it is not possible to do without experimental studies.

Designing heat exchangers with a low fouling rate will only delay the onset of the problem. It is therefore important to know how to detect it by monitoring the performance of the exchanger [18]. Then cleaning methods can be put in place at the right time.

In the metallurgy plants, one of the most used methods is the steel shot rain on the exchanger. This technical solution is quite aggressive for the exchanger but allows it to keep decent performance for a moderate period of time. In the past, the economic choice to make robust and cheap heat exchangers in bare tubes was made. This choice is questioned today. This is why we are studying the evolution of the performance of specially designed finned exchangers that are prone to fouling in metallurgy industries.

\section{Experimental set-up}

\subsection{Test-bench design}

In order to study the evolution of the performance of heat exchangers as a function of the fouling, we have built a closed loop wind tunnel capable of working at relatively high temperatures with a dust injection system. The block diagram is shown in Fig. 1, and a representation of the layout is in Fig. 2.

Air flow in the main loop is generated by a centrifugal fan of $11 \mathrm{~kW}$.

A large group of electric resistances $(20.4 \mathrm{~kW})$ makes it possible to increase the temperature of the air up to $200{ }^{\circ} \mathrm{C}$. After having been seeded with dust in a venturi shaped section, the air passes through the heat exchanger.

Then, the air is filtered thanks to a cyclonic separator to remove the particles that did not settle on the exchanger. A cartridge filter was tested to improve filtration for the smallest particles. This filter was not retained due to the relative short time to the obstruction of the filters when compared to the duration of the tests.

Also, the heat exchanger is supplied by a closed loop of water. The warm water is then cooled down with an outside air cooler.

The power of the electric resistance heaters is regulated to keep the temperature in the air loop constant during the test.

The air and water flowrates are adjusted by varying the speed of the fan and the outlet pressure at the pump at the start of the test (after warming up). The flow measurements during the tests showed a very small drift over time, despite the fouling as it can be observed in Fig. 3.

For each test the water and air flow are brought to a stable condition without dust injection. After, water inlet is above $60{ }^{\circ} \mathrm{C}$ (to avoid condensation); then the dust injection is started. Before each test, the air ducts are cleaned over in order to maintain a similar air surface for all the tests. However, the rest of the air loop is not cleaned until the series of tests is finished. At the end of all the tests, the dust deposit is around $20 \mathrm{~mm}$ thick at the bottom of the inlet air duct and at the outlet air duct, but the sides and top of those air ducts have so significant dust deposits.

\subsection{Heat exchangers tested}

The objective is to characterize the behaviour of heat exchangers that are made to collect heat from hot $\left(200{ }^{\circ} \mathrm{C}\right)$ and dust loaded (from 2 to $20 \mathrm{~g} . \mathrm{Nm}^{-3}$ ) air streams. Currently, this 


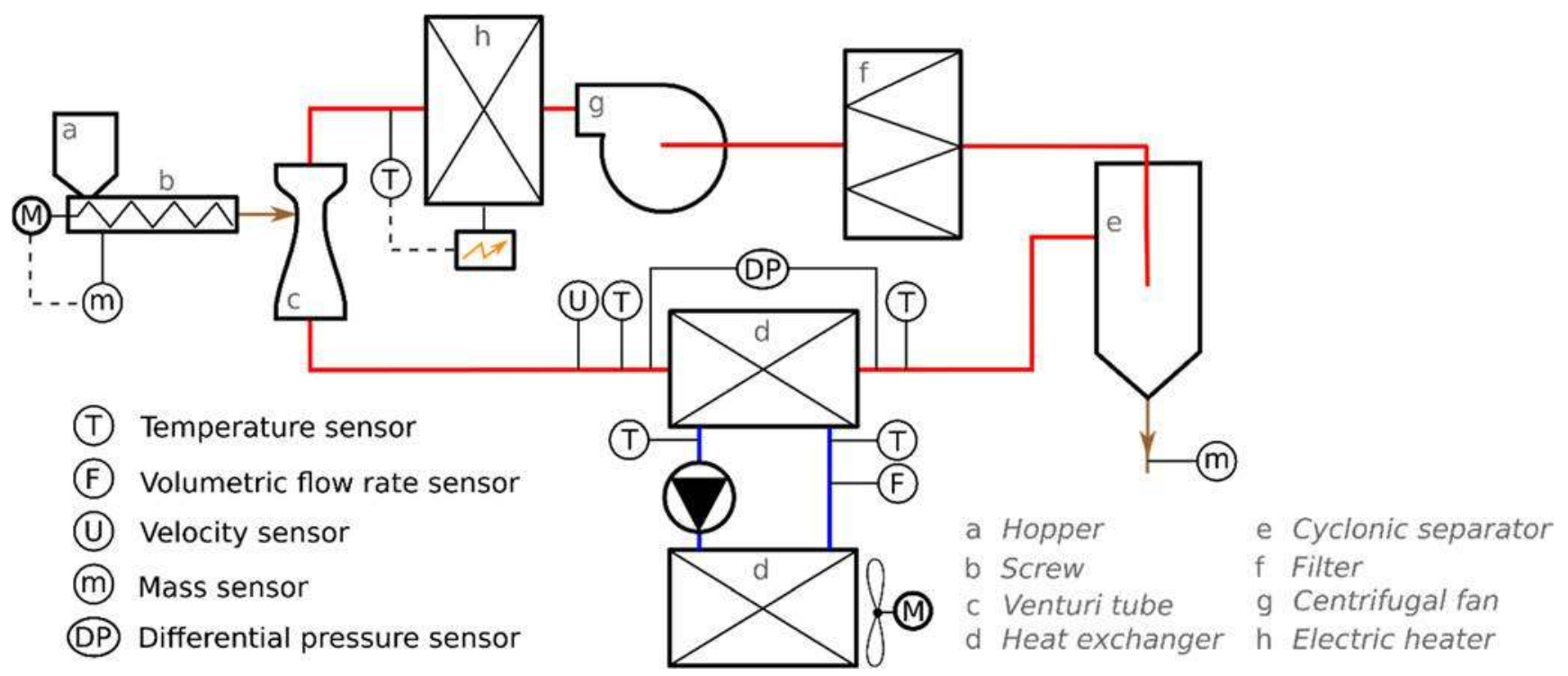

Fig. 1 Block diagram of the setup

kind of heat exchanger has poor performances due to fouling and thus needs to be regularly cleaned. The robust design of the tubes and fins meets the objective of mechanical and chemical resistance needed for these purposes. All parts of the heat exchangers are made with $316 \mathrm{~L}$ stainless steel.

Five geometry models (called G1, G2, G3, G4 and G5) have been made for this parametric analysis. The G1 is made with bare tubes. The others are made with finned tubes. The diameter, the width and the density of the fins have been studied. The five exchangers are presented in Fig. 4. Standard finned tubes cannot be used due to their poor mechanical resistance with regard to corrosion at high temperature and the use of steel shots for cleaning.

The fins are in close contact with the tube but welded only in four points (representing $25 \%$ of the surface contact). Tube bundle arrangements are an inline array: rows are aligned with row $n^{\circ} 1$ regarding the air flow. The number of rows and columns have been designed in order to ensure an identical pressure drop for all the geometries in order to guarantee the same air flow rate for each geometry. The heat transfer fluid is water

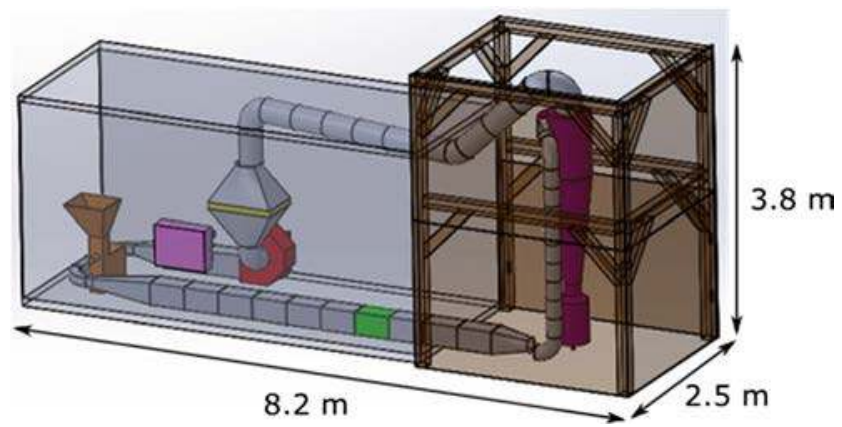

Fig. 2 Design of the setup flowing through each tube. Geometric parameters are presented in Table 1.

Each heat exchanger includes two steel flanges, which are used to distribute and collect the water flow between the tubes. The water flow uses 2 to 3 distributions in each heat exchanger.

\subsection{Dust and dust injection}

The dust was collected at an industrial production site, the silicon factory FERROPEM. The particles are composed mainly of silica. The particles' density and size distribution are given in Table 2 .

To control the injection of dust, a gravimetric screw weigh feeder with a hopper volume of $62 \mathrm{~L}$ was used. The rotation speed of the screw is regulated according to the time evolution

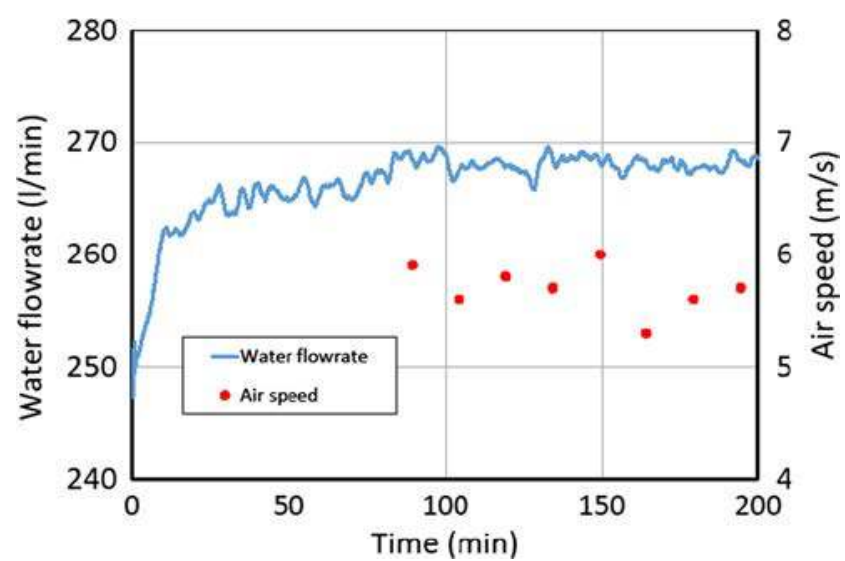

Fig. 3 Temporal evolution of measured water flowrate and air speed during a test for the G2 heat exchanger 
Fig. 4 Configuration of the heat exchangers tested; a Model G1, b Model G2, c Model G3, d Model G4, e Model G5

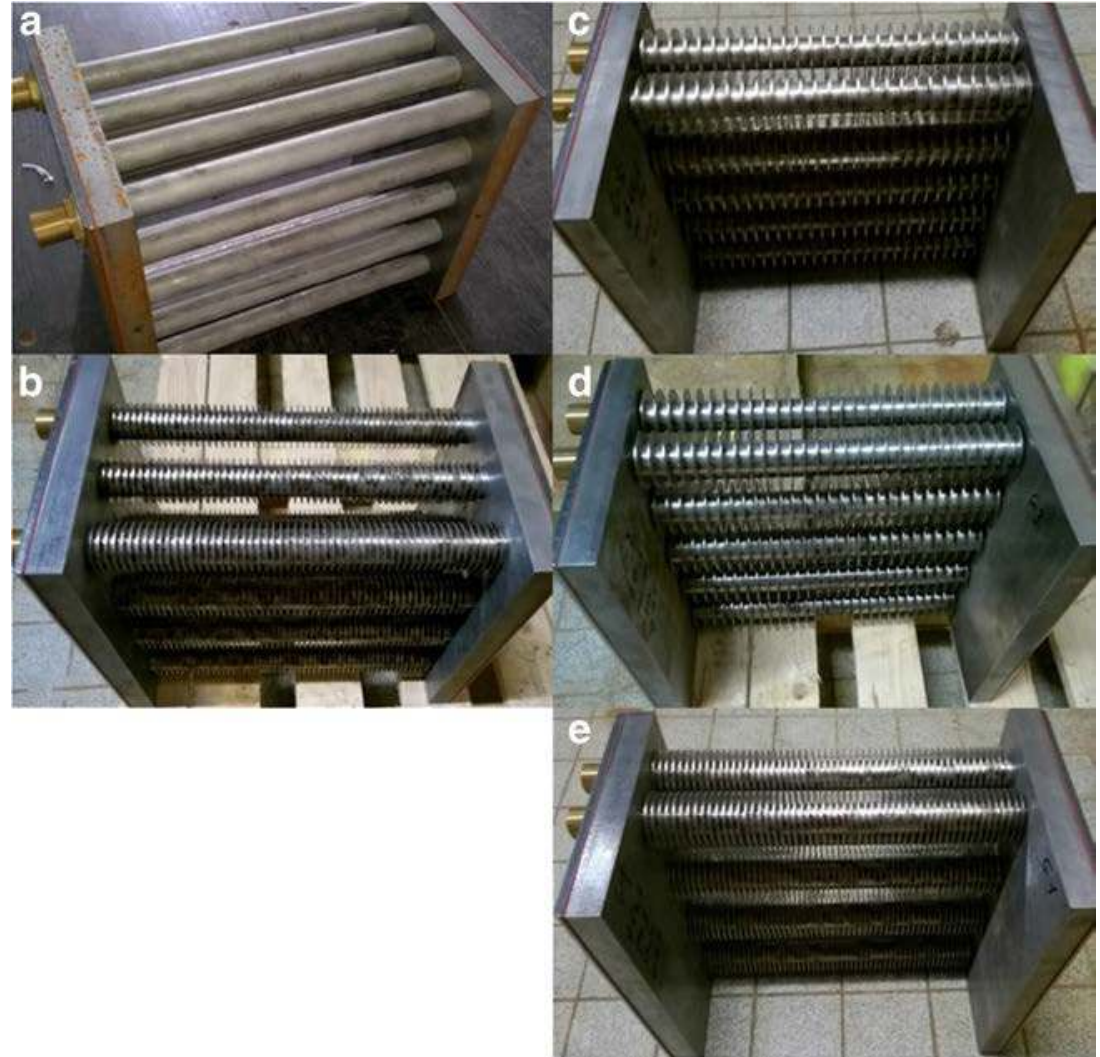

of the mass in the hopper in order to obtain a constant mass flow rate of dust.

The dust is sent by the screw into a vertical tube connected to a Venturi tube. The use of a Venturi tube has two advantages: it creates a pressure at the injection point lower than the atmospheric pressure, which ensures that the dust is injected into the setup; it also makes it possible to obtain very high flow speeds (7.7 times faster than the

Table 1 Geometric parameters of the heat exchangers

\begin{tabular}{|c|c|c|c|c|c|c|}
\hline Geometrical parameters & Unit & Model G1 & Model G2 & Model G3 & Model G4 & Model G5 \\
\hline Number of tubes & - & 20 & 12 & 10 & 10 & 8 \\
\hline Number of columns & - & 4 & 3 & 2 & 2 & 2 \\
\hline Number of rows & - & 5 & 4 & 5 & 5 & 4 \\
\hline Space between each column & $\mathrm{cm}$ & 6.00 & 7.50 & 6.00 & 6.00 & 7.50 \\
\hline Space between each row & $\mathrm{cm}$ & 4.50 & 6.00 & 5.00 & 5.00 & 5.00 \\
\hline Exchanger depth & $\mathrm{cm}$ & 18.0 & 18.0 & 10.0 & 10.0 & 10.0 \\
\hline Heat exchanger width & $\mathrm{cm}$ & 30.0 & 30.0 & 30.0 & 30.0 & 30.0 \\
\hline Tube exterior diameter & $\mathrm{cm}$ & 2.54 & 2.54 & 2.54 & 2.54 & 2.54 \\
\hline Tube interior diameter & $\mathrm{cm}$ & 2.36 & 2.36 & 2.36 & 2.36 & 2.36 \\
\hline Number of fins per tube & - & - & 55 & 28 & 28 & 55 \\
\hline Fin diameter & $\mathrm{cm}$ & - & 3.54 & 4.54 & 4.54 & 4.54 \\
\hline Fin thickness & $\mathrm{mm}$ & - & 0.80 & 1.50 & 0.80 & 0.80 \\
\hline Total exterior exchange surface & $\mathrm{m}^{2}$ & 0.48 & 0.88 & 0.83 & 0.84 & 1.14 \\
\hline Total exterior bare tubes surface & $\mathrm{m}^{2}$ & 0.48 & 0.29 & 0.24 & 0.24 & 0.19 \\
\hline $\begin{array}{l}\text { Ratio total exterior exchange surface to } \\
\text { total exterior bare tubes surface }\end{array}$ & - & 1.00 & 3.00 & 3.46 & 3.50 & 6.00 \\
\hline Exchanger volume & 1 & 16.2 & 16.2 & 9.0 & 9.0 & 9.0 \\
\hline Exchanger mass & $\mathrm{kg}$ & 6.5 & 5.9 & 7.0 & 5.2 & 5.7 \\
\hline
\end{tabular}


Table 2 Density and size distribution of the dust used

\begin{tabular}{lll}
\hline Characteristics & FERROPEM & $\begin{array}{l}\text { Cyclonic separator } \\
\text { efficiency }\end{array}$ \\
\hline Density & $1530 \mathrm{~kg} \cdot \mathrm{m}^{-3}$ & \\
$\mathrm{~d}<1 \mu \mathrm{m}$ & $15 \%_{\mathrm{vol}}$ & $<17 \%_{\mathrm{vol}}$ \\
$1 \mu \mathrm{m}<\mathrm{d}<3 \mu \mathrm{m}$ & $11 \%_{\mathrm{vol}}$ & $48 \%_{\mathrm{vol}}$ \\
$3 \mu \mathrm{m}<\mathrm{d}<5 \mu \mathrm{m}$ & $6 \%_{\mathrm{vol}}$ & $76 \%_{\mathrm{vol}}$ \\
$5 \mu \mathrm{m}<\mathrm{d}<8 \mu \mathrm{m}$ & $7 \%_{\mathrm{vol}}$ & $90 \%_{\mathrm{vol}}$ \\
$8 \mu \mathrm{m}<\mathrm{d}<15 \mu \mathrm{m}$ & $8 \%_{\mathrm{vol}}$ & $96 \%_{\mathrm{vol}}$ \\
$15 \mu \mathrm{m}<\mathrm{d}<25 \mu \mathrm{m}$ & $10 \%_{\mathrm{vol}}$ & $98 \%_{\mathrm{vol}}$ \\
$25 \mu \mathrm{m}<\mathrm{d}<40 \mu \mathrm{m}$ & $10 \%_{\mathrm{vol}}$ & $99 \%_{\mathrm{vol}}$ \\
$40 \mu \mathrm{m}<\mathrm{d}<75 \mu \mathrm{m}$ & $11 \%_{\mathrm{vol}}$ & $100 \%_{\mathrm{vol}}$ \\
$75 \mu \mathrm{m}<\mathrm{d}<250 \mu \mathrm{m}$ & $22 \%_{\mathrm{vol}}$ & $100 \%_{\mathrm{vol}}$ \\
$250 \mu \mathrm{m}<\mathrm{d}$ & $0 \%_{\mathrm{vol}}$ & $100 \%_{\mathrm{vol}}$ \\
\hline
\end{tabular}

speed of the nominal pipe) which is beneficial to the dispersion of the dust.

\subsection{Efficiency of the cyclonic separator}

The cyclonic separator has been designed following the rules proposed by Stairmand [19]. The performance of the cyclonic separator has been determined from W. H. Koch et al. [20] and is shown in Table 2.

\subsection{Metrology}

\subsubsection{Water temperature}

The water loop is equipped with two PT100 4-wire class 1/10 DIN probes. A test was carried out without any air flow, and the temperature difference between inlet and outlet was less than $0.20^{\circ} \mathrm{C}$ at $20^{\circ} \mathrm{C}$.

\subsubsection{Air temperature}

The air loop is equipped with two PT100 4-wire class 1/10 DIN probes. We carried out a test without any water flow. The temperature difference between inlet and outlet was less than $0.15^{\circ} \mathrm{C}$ for a mean temperature of $50^{\circ} \mathrm{C}$. An additional PT100 probe is used to regulate the temperature of the loop.

\subsubsection{Water flowrate}

The water loop is equipped with an electromagnetic flowmeter (PROMAG 10H15) with a 4-20 mA output signal in relation to the flow. The global uncertainty on this measurement is estimated to be $\pm 1.5 \%$ of the measured water flow.

\subsubsection{Air flowrate}

A Pitot probe is used to calculate the speed (and therefore the flowrate) of the air in the test vein. It is placed in the middle of the air inlet section at $0.5 \mathrm{~m}$ before the entry of the heat exchanger.

A 20-point speed map of the air flow has been made at the same section. These measurements allowed us to observe the distribution of the flow in the pipe. This map leads to a correction factor $\left(\mathrm{K}_{2}\right)$ of 0.90 between the local air speed given by the pitot, and the average speed of the air, which is used for the calculation of power loss through the air side without dust injection.

The Pitot probe, being sensitive to fouling, was inserted every $5 \mathrm{~min}$ for $30 \mathrm{~s}$.

At the end of all the tests a layer of dust of $20 \mathrm{~mm}$ thick is observed at the bottom of the rectangular duct situated between the dust injection point and the heat exchanger inlet section. This layer tends to concentrate the air flow in the free part of the duct, leaving the bottom tubes of the heat exchanger with less air flow.

\subsubsection{Pressure drop}

A differential manometers was used to measure the pressure drop between the air inlet and air outlet of the heat exchanger. Both pressure points are $0.5 \mathrm{~m}$ away from the heat exchanger in the direction of air flow. The measurement uncertainty is $1.0 \mathrm{~Pa}$.

Liquid column manometers are used to verify that the installation is not subject to any long-term fouling.

\subsubsection{Data recording}

These different sensors are connected to an acquisition unit (YOKOGAWA FX 100) allowing the recording of measurements at a frequency of $0.5 \mathrm{~Hz}$. Measurements were averaged over $2 \mathrm{~min}$ before being displayed or exploited.

\subsection{Operating conditions}

The tests presented were carried out with similar experimental conditions presented in Table 3.

Table 3 Targeted operation conditions

\begin{tabular}{lrl}
\hline Characteristics & & Unit \\
\hline Air velocity & 6 & $\mathrm{~m} \cdot \mathrm{s}^{-1}$ \\
Air inlet temperature & 190 & ${ }^{\circ} \mathrm{C}$ \\
Dust mass flowrate & 38 & $\mathrm{~g} \cdot \mathrm{min}^{-1}$ \\
Water volumetric flowrate & 250 & $1 . \mathrm{h}^{-1}$ \\
\hline
\end{tabular}




\section{Data analysis}

The density of the air is calculated using the ideal gas law, expressed as a function of temperature and pressure [21]:

$\rho_{\mathrm{a}}(\mathrm{T}, \mathrm{p})=\frac{\mathrm{M}}{\mathrm{R}} \frac{\mathrm{p}}{\mathrm{T}}$

The air velocity in the duct is captured by the Pitot tubes and calculated with Eq. 2, where $\mathrm{K}_{1}$ is a correction coefficient provided by the Pitot tubes manufacturer and $\mathrm{K}_{2}$ is a correction coefficient provided by our calibration (see Section 2.5.4)

$\mathrm{u}_{\mathrm{a}}=\mathrm{K}_{1} \cdot \mathrm{K}_{2} \sqrt{\frac{2 \Delta \mathrm{p}}{\rho_{\mathrm{a}}}}$

The rate of heat that is added to the water is given by Eq. 3 [21].

$\dot{\mathrm{Q}}_{\mathrm{w}}=\rho_{\mathrm{w}} \mathrm{c}_{\mathrm{p}, \mathrm{w}} \dot{\mathrm{V}}_{\mathrm{w}}\left(\mathrm{T}_{\mathrm{w}, \mathrm{i}}-\mathrm{T}_{\mathrm{w}, \mathrm{o}}\right)$

The thermophysical properties of water were evaluated by taking the average temperature of the water and referring to the table proposed by [22].

In order to determine a heat transfer coefficient for the studied exchangers the method of the logarithmic mean temperature difference was used [23]. The logarithmic mean temperature difference was calculated by considering the heat exchanger as a double pipe pure counter flow heat exchanger. Indeed, the correction factor for taking into account the crossflow configuration, has been calculated, to a value very close to one.

$\Delta \mathrm{T}_{\mathrm{LM}}=\frac{\left(\mathrm{T}_{\mathrm{a}, \mathrm{i}}-\mathrm{T}_{\mathrm{w}, \mathrm{o}}\right)-\left(\mathrm{T}_{\mathrm{a}, \mathrm{o}}-\mathrm{T}_{\mathrm{w}, \mathrm{i}}\right)}{\ln \left(\frac{\mathrm{T}_{\mathrm{a}, \mathrm{i}}-\mathrm{T}_{\mathrm{w}, \mathrm{o}}}{\mathrm{T}_{\mathrm{a}, \mathrm{o}}-\mathrm{T}_{\mathrm{w}, \mathrm{i}}}\right)}$

In order to provide indicators to determine the heat exchanger geometries allowing an intensification of the heat transfer, a heat transfer coefficient (Eq. 5), a specific heat transfer coefficient (Eq. 6) and volumetric heat transfer coefficient (Eq. 7) have been calculated and are presented later. The surface area used in Eq. 5 is the outside surface of the bare tubes.

$\mathrm{Us}=\frac{\dot{\mathrm{Q}}_{\mathrm{w}}}{\mathrm{S} \Delta \mathrm{T}_{\mathrm{LM}}}$

$\mathrm{Um}=\frac{\dot{\mathrm{Q}}_{\mathrm{w}}}{\mathrm{m} \Delta \mathrm{T}_{\mathrm{LM}}}$

$\mathrm{Uv}=\frac{\dot{\mathrm{Q}}_{\mathrm{w}}}{\mathrm{V} \Delta \mathrm{T}_{\mathrm{LM}}}$

\section{Results}

\subsection{Presentation of the measurements}

As described above, pressure drop and heat transfer tests were carried out under fouled conditions. Figure 5 presents the evolution of temperatures for a typical test (test carried out with the G2 geometry). The setup took less than an hour to warm up and to reach a steady state. Then, a stabilization phase of around $30 \mathrm{~min}$ has been maintained. The injection of dust started for this test at $85 \mathrm{~min}$ and lasted until the end of the test.

As can be seen in Fig. 5, the regulation of the air temperature is working properly. The air temperature upstream of the heat exchanger is at a constant temperature of $190{ }^{\circ} \mathrm{C}$. The small oscillations observable from $150 \mathrm{~min}$ on wards are due to a slight fouling of the heating system, including the temperature sensor. This fouling affects the PID parameters.

During the fouling phase, the performance of the heat exchanger decreases with time. The cooling circuit is less and less heated which explains the gradual decline in the temperature of the water loop.

The heat transfer coefficient (Eq. 5) is shown in Fig. 6. This coefficient changes strongly in the first minutes. This is due to the transient phase of the heat regime of the exchanger. Once this transitional phase has passed, the heat transfer coefficient is stable until the dust is injected. The injection of dust has an immediate effect on the transfer coefficient, which decreases monotonically throughout the experiment.

\subsection{Fouling morphologies}

The heat exchangers fouling after the tests have been observed. Similar fouling shapes has be found for all finned tubes geometries (see Fig. 7 for G1 and G2). The dust particles are mainly deposited near the upwind stagnation points. On the first column, the stagnation point is in the middle of the tube. But for the next column, due to the wake, two stagnation

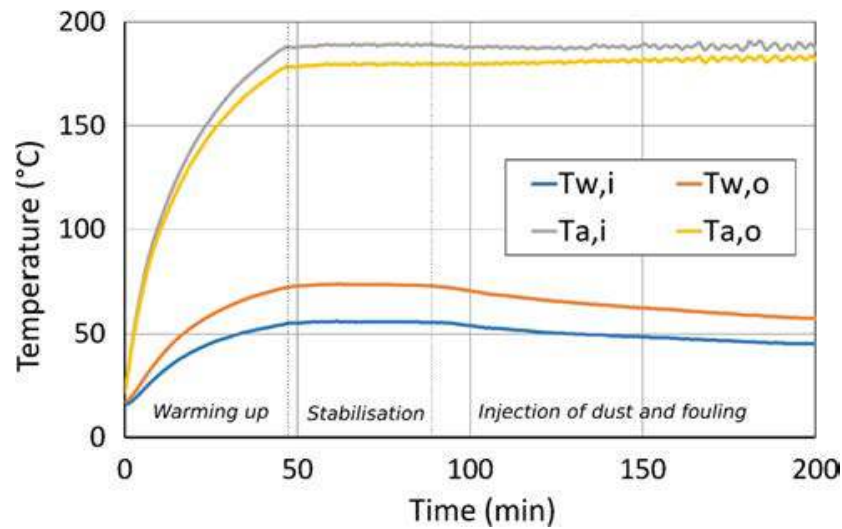

Fig. 5 Time evolution of air and water temperatures during a test for the G2 heat exchanger 


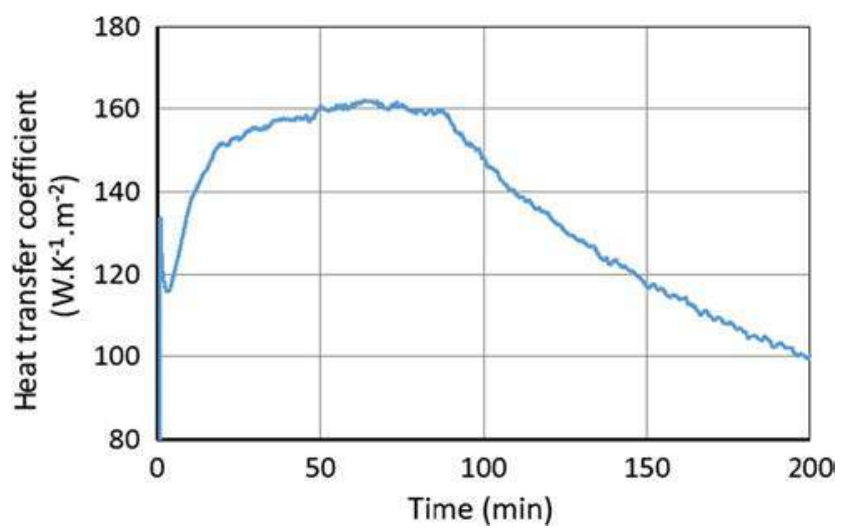

Fig. 6 Time evolution of the heat transfer coefficient for the G2 heat exchanger

points exist. The average thickness of the fouling layer seems to be constant from one column to another. An asymmetry is still observable in the top row and the bottom row.

The presence of fins does not strongly affect the dust deposition location. It can be seen that dust accumulates mainly between the fins at the point of impact of the flow. A thin layer of dust, substantially identical in thickness to that on the top and bottom of the tube, is still present on the surfaces of the fins.

Our observations are in agreement with the experimental results obtained by Y. Wand et al. [24] for a single bare tube and with the numerical results obtained by S.-Z Tang et al. [14].

\subsection{Pressure drop evolution (air flow)}

The evolution of the pressure drop averaged over $30 \mathrm{~s}$ for each geometry is shown in Fig. 8. It can be seen that the pressure drop decreases during the temperature rise phase of the installation. This evolution is due to changes in the properties of the air, particularly the density: $\rho_{20^{\circ} \mathrm{C}}=1.20 \mathrm{~kg} \cdot \mathrm{m}^{-3} ; \rho_{190^{\circ} \mathrm{C}}=$ $0.76 \mathrm{~kg} \cdot \mathrm{m}^{-3}$.

During the fouling phase, the pressure drop does not seem to increase, contrary to what could be expected. The presence

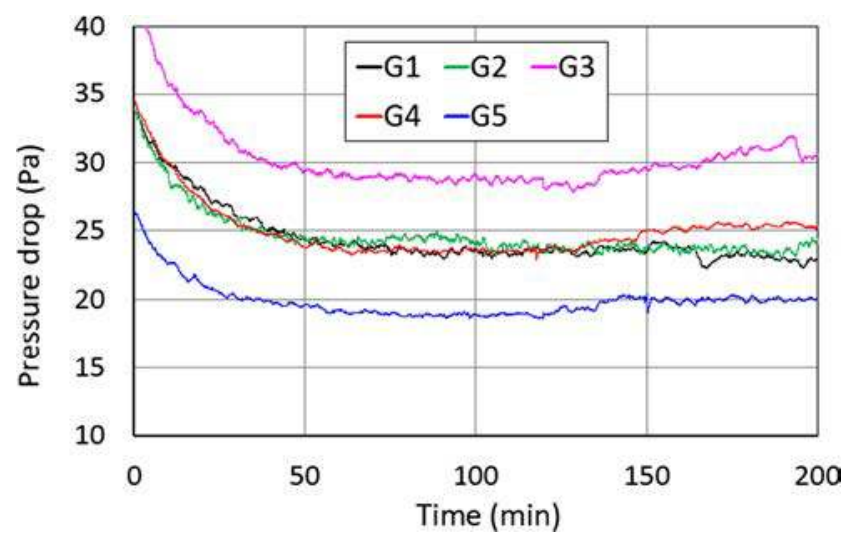

Fig. 8 Time evolution of the pressure drop

of dust in the air does not seem to have a significantly impact on the pressure drop, which is certainly due to a low concentration of dust. Dust does not seem to have a long-term impact either. This can be explained firstly by the fact that, for this type of exchanger, the thickness of the fouling is small compared to the cross section of the flow. In addition, the accumulation of dust, mainly on the upstream face and in a smaller quantity on the downstream face, may improve the aerodynamics of the tubes.

For each geometries, the pressure are roughly the same. This result was expected since we had to size the number of rows and columns in order to obtain, a priori, the same pressure drop for each of the exchangers.

\subsection{Reproducibility}

In order to verify that the studied phenomena are reproducible, we have, for some geometries, carried out the experiment several times. In the remainder of this document we present, for the G2 geometry, the results obtained for two tests. We found a variation in measurements of up to $15 \%$ of the heat transfer coefficient. However, the evolution of this coefficient is always respected. It is therefore reasonable to assume that
Fig. 7 Photographs of heat exchangers after fouling test. a G1; b G2

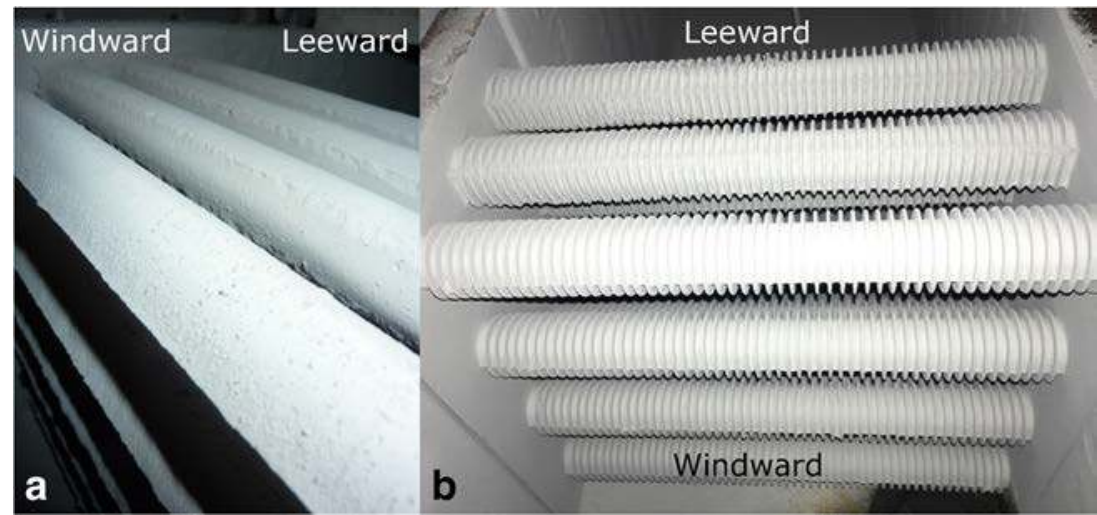




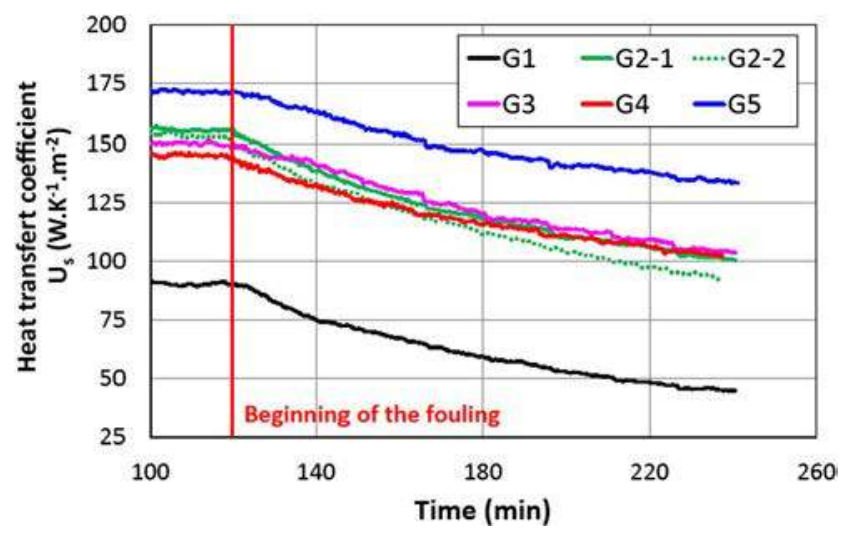

Fig. 9 Evolution of the heat transfer coefficient

fouling, on the scale of a heat exchanger, is not random but follows laws of physical behavior.

\subsection{Evolution of the heat transfer coefficient}

The heat transfer coefficients obtained from Eqs. 5, 6 and 7 are respectively displayed in Figs. 8, 9 and 10. In order to facilitate the comparison, we synchronized the measurements so that the beginning of the fouling start at the same time for each test.

For each geometry, it is observed that the heat transfer coefficients are constant during the first minutes that is to say before the beginning of the fouling. This proves the stability of our device. Then, after the fouling begins, the thermal performances of all heat exchangers decrease. The characteristics of these declines are discussed in more detail in the next section of this report.

Some geometries have better transfer coefficients than others. The values of these transfer coefficients and the way in which they are decreasing are important to know in order to optimize the exchanger design. From these measurements it is possible to determine the best geometry according to the constraints of uses.

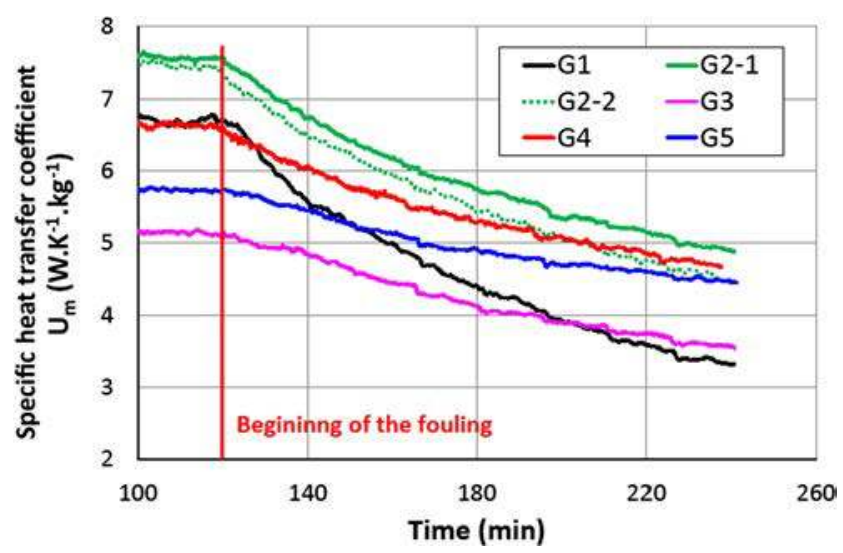

Fig. 10 Evolution of the specific heat transfer coefficient
If we look at the heat transfer coefficient, which is commonly used, it is obvious that the use of bare tubes (G1) is not a good choice, because even after $2 \mathrm{~h}$ of fouling all other geometries have better performances than the unfouled bare tubes. If we choose this optimization criterion, it is the geometry G5, with highest fin surface, that should be selected.

If there are constraints on the total mass of the exchanger, it is from Fig. 9 that the optimal geometry is to be identified. This time it is the G2 geometry that seems to be optimal, although its sharp decline suggests that the G5 geometry would perform better after 3 to $4 \mathrm{~h}$ of fouling. Once again a finned tube heat exchanger is preferable to bare tubes.

The size is often a dimensioning criterion. It is from Fig. 10 that we will determine what geometry is the most efficient. The geometry G5 is again the most efficient after a few hours of fouling (Fig. 11).

\subsection{Analysis of the temporal evolution of the heat transfer coefficient}

In order to analyze the decrease over time of heat transfer coefficients, the change in the ratio R (see Eq. 8) of the heat transfer coefficients measured during fouling by the transfer coefficient before fouling is plotted in Fig. 12.

$\mathrm{R}\left(\mathrm{t}-\mathrm{t}_{0}\right)=\frac{\mathrm{Us}\left(\mathrm{t}-\mathrm{t}_{0}\right)}{\mathrm{Us}\left(\mathrm{t}_{0}\right)}$

For each geometry this ratio decreases in an asymptotic manner. Therefore, the heat transfer coefficient can be fitted by an exponential function, as shown in Eq. 9. The time constant, $\tau$, gives an indication of the speed at which a heat exchanger gets fouled while the value $\mathrm{k}$ gives an indication of the performance of the heat exchanger after using it for a long time.

$\mathrm{R}\left(\mathrm{t}-\mathrm{t}_{0}\right)=1-\mathrm{k}\left(1-\mathrm{e}^{\left(\mathrm{t}_{0}-\mathrm{t}\right)} / \tau\right)$

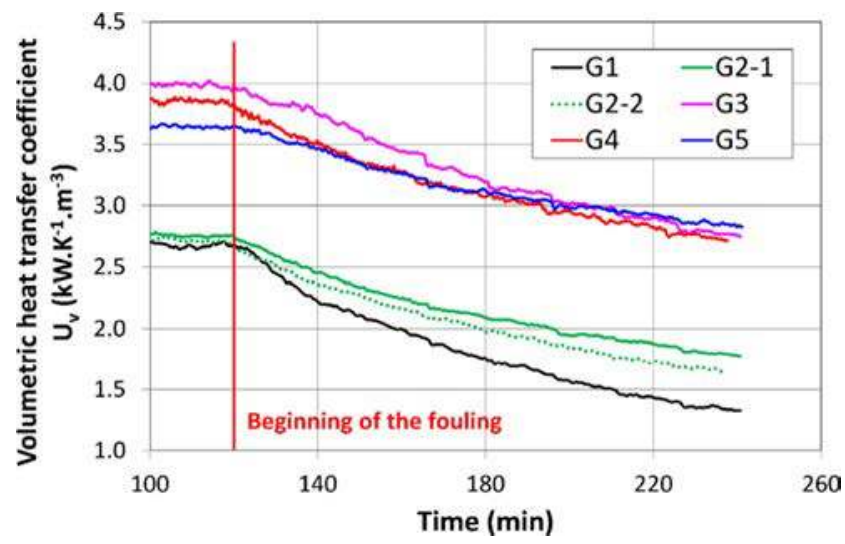

Fig. 11 Evolution of the volumetric heat transfer coefficient 


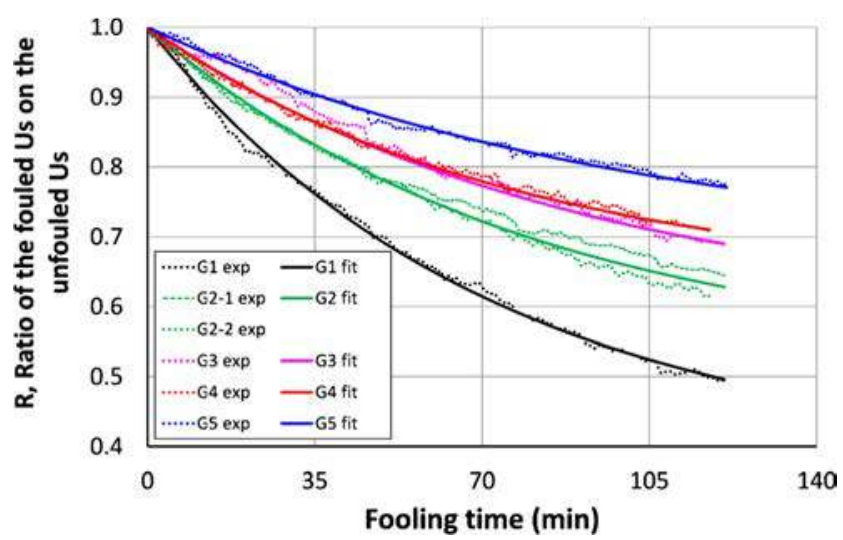

Fig. 12 Time evolution of the ratio of the fouled and unfouled heat transfer coefficients, experimental and fitting results

The results are plotted in Fig. 12 and the value of the constants $\tau$ and $\mathrm{k}$ are reported in Table 4 . It can be seen that the fitting line fits well with the experimental results.

This asymptotic evolution was also obtained numerically by Wang et al. [13]. In their model, they took into account the possibility for transported particles to be deposited on walls, but also the possibility for deposited particles to be removed from walls by the flow. At first only the phenomenon of deposition exists. Then, the removal rate increases until it equals the deposition rate. A limited deposit thickness is then reached.

From his numerical results, obtained for a geometry and conditions comparable to ours (air velocity of $5 \mathrm{~m} . \mathrm{s}^{-1}$, mean particle diameter of $5 \mu \mathrm{m}$ and particle density of $3110 \mathrm{~kg} \cdot \mathrm{m}^{-3}$ ), they obtain a time constant $(56 \mathrm{~min})$ of the same order of magnitude as ours. Our experimental results are in agreement to their numerical model.

It is nevertheless important to keep in mind that these results are obtained from tests carried out over short periods of time compared to the lifespan of an exchanger. It is probable that hardening, compaction phenomena of the deposition layer, and the slow evolution of the shape cannot be observed with these time scales.

In order to determine which geometry of heat exchanger is the most suitable, the heat transfer coefficient measured without fouling should not be used. The asymptotic value of the heat transfer coefficient is more appropriated. Here again, the geometry G5, where the fin surface is the highest, seems to be

Table 4 Values of constant $\tau$ and $\mathrm{k}$ for the different geometries (see Eq. 9)

\begin{tabular}{llc}
\hline Geometries & $\mathrm{k}$ & $\tau(\mathrm{min})$ \\
\hline G1 & 0.62 & 72 \\
G2 & 0.48 & 81 \\
G3 & 0.42 & 90 \\
G4 & 0.37 & 77 \\
G5 & 0.33 & 102 \\
\hline
\end{tabular}

the most favorable. In addition to having a good performance, it also has the lowest fouling speed. Even more surprising, our results suggest that a heat exchanger with finned tubes has always a better performance, even fouled, than an unfouled bare tube heat exchanger. The reason is that the fouling is not equal on all the surfaces. The dust thickness is less on the fins than on the tubes. Therefore, despite a fin efficiency reduced, the fins tubes heat exchanger is always a better option. The limit of this affirmation is when the fin spacing is small enough to be clogged by the dust.

\section{Conclusions}

The present study was meant to analyze the influence of the fouling of heat exchangers under the conditions that best represent the industrial environments during the recovery of waste heat on the evacuation of the chimneys. The main objective was to determine if the use of fins is an interesting choice when there is a high risk of fouling. A test bench has been built which makes it possible to obtain fouling atmospheres from dust at temperatures up to $200^{\circ} \mathrm{C}$.

The experimental approach was based on the temporal monitoring of the flow and thermal performances of the exchangers studied using the logarithmic mean temperature difference method. Our results are stable before fouling and repeatable, which is the proof that our method worked well.

Our observations of the formation of the fouling layer show a very small increase in pressure losses during the fouling.

Analysis of the heat transfer coefficients during fouling revealed that the use of finned tubes is a good choice. Although the fins are prone to fouling, even with the drop in performance due to fouling, the fined tubes are still better than bare tubes. It is now possible to consider finding the optimal geometry for different possible scenarios: design constraints, cleaning frequency and construction cost.

Acknowledgements On behalf of all authors, the corresponding author states that there is no conflict of interest.

The authors would like to thank the Icam students, Olexandr BAL, Baptiste GENAUZEAU, William LE GOFF, Mathilde CLEMENT, Simon PASQUIER, Luc BLEUZEN, Léo BEDERE, Laurent DESFLANS, Quentin SAVINA, Samuel GOBIN, and Alexandra ANSELIN for their precious participations to the study. This work was partially funded by ADEME and TOTAL in the frame of RTD program "Efficacité énergétique dans l'industrie".

\section{References}

1. Mirzaei M, Hajabdollahi H, Fadakar H (2017) Multi-objective optimization of shell-and-tube heat exchanger by constructal theory. Appl Therm Eng 125:9-19

2. Imran M, Pambudi NA, Farooq M (2017) Thermal and hydraulic optimization of plate heat exchanger using multi 
objective genetic algorithm. Case studies in Thermal Engineering 10:570-578

3. Raja B, Patel V, Jhala R (2017) Thermal design and optimization of fin-and-tube heat exchanger using heat transfer search algorithm. Thermal Science and Engineering Progress 4:45-57

4. Zubair SM, Sheikh AK, Younas M, Budair M (2000) A risk based heat exchanger analysis subject to fouling part I: performance evaluation. Energy 25:427-443

5. Bell IH, Groll EA (2011) Air-side particulate fouling of microchannel heat exchangers: experimental comparison of airside pressure drop and heat transfer with plate-fin heat exchanger. Appl Therm Eng 31:742-749

6. Zhang C, Tang Z, Zhang Z, Shi J, Chen J, Zhang M (2018) Impact of airside fouling on microchannel heat exchangers. Appl Therm Eng 128:42-50

7. Song J, Liu Z, Ma Z, Zhang J (2017) Experimental investigation of convectve heat transfer from sewage in heat exchange pipes and the construction of a fouling resistance-based mathematical model. Energy and Buildings 150:412-420

8. Chen H, Wang Y, Zhao Q, Ma H, Li Y, Chen Z (2014) Experimental investigation of heat transfer and pressure drop characteristics of $\mathrm{H}$ type finned banks. Energies 7:7094-7104

9. Baxter L, De Sollar R (1993) A mechanistic description of ash deposition during pulverized coal combustion: predictions compared with observations. Fuel 72:1411-1418

10. Van Beek M, Rindt C, Wijers J, Van Steenhoven A (2006) Rebound characteristics for $50-\mu \mathrm{m}$ particles impacting a powdery deposit. Powder Technol 165:53-64

11. Lee B, Fletcher C, Shin S, Kwon S (2002) Computational study of fouling deposit due to surface-coated particles in coal-fired power utiliy boilers. Fuel 81:2001-2008

12. Han H, He Y-L, Tao W-Q, Li Y-S (2014) A parameter study of tube bundle heat exchangers for fouling rate reduction. Heat Mass Transf 72:210-221

13. Wang F-L, He Y-L, Tong Z-X, Tang S-Z (2017) Real-time fouling characteristics of a typical heat exchanger used in the waste heat recovery systems. Heat Mass Transf 104: 774-786

14. Tang S-Z, Wang F, Ren Q, He Y-L (2017) Fouling characteristics analysis and morphology prediction of heat exchangers with a particulate fouling model considering deposition and removal mechanisms. Fuel 203:725-738

15. Wang F-L, He YL, Tang S-Z, Tong Z-X (2017) Parameter study on the fouling characteristics of the H-type finned tube heat exchangers. Heat Mass Transf 112:367-378

16. Fu L, Liu P, Li G (2017) Numerical investigation on ash fouling characteristics of flue gas heat exchanger. Appl Therm Eng 123: 891-900

17. li M-J, Tang S-Z, Wang F-L, Zhao Q-X, Tao W-Q (2017) Gas-side fouling, erosion and corrosion of heat exchangers for middle/low temperature waste heat utilization: a review on simulation and experiment. Appl Therm Eng 126:737-761

18. Palmer K, Hale W, Such K, Shea B, Bollas GM (2016) Optimal design of tests for heat exchanger fouling identification. Appl Therm Eng 95:382-393

19. Englund HM, Calvert S (1984) Handbook of air pollution technology. Wiley, New York

20. Koch WH, Licht WL (1977) New design approach boosts cyclone efficiency. Chemical Egineering 84:80-88

21. Moran MJ, Shapiro HN (2003) Fundamentals of engineering thermodynamics, 5th edn. Wiley, New York

22. Thermexcel [Online]. Available: https://www.thermexcel.com. Accessed 15 Apr 2018

23. Incropera FP, DeWitt DP, Bergman TL, Lavine AS (2002) Fundamentals of heat and mass transfer 6th edition. Wiley, New York

24. Wang Y et al (2013) Experimental study on SP ash deposition characteristics on the surface of convection bank bundle. In: Collected works of 2012 youth forum of power engineering. Chinese Society of Power Engineering

Publisher's note Springer Nature remains neutral with regard to jurisdictional claims in published maps and institutional affiliations. 